Journal of Engineering and Applied Sciences 14 (22): 8232-8236, 2019

ISSN: 1816-949X

(C) Medwell Journals, 2019

\title{
Design for Safety Concept for Ferries Operating on Indonesian Waters
}

\author{
Sunaryo and Daniel Adieu \\ Department of Mechanical Engineering, Naval Architecture and Marine Engineering, \\ Universitas of Indonesia, Kampus UI, 16424 Depok, Indonesia, naryo@eng.ui.ac.id
}

\begin{abstract}
The study is intended to propose a concept of ferry design that would cater all aspects of safety for its operation. The study is motivated by the challenge of so, many ship accidents occurred on Indonesian waters, crossing ferries in particular which in some cases involving a great number of human lives. Available accident data are used to identify the types and sources of accidents, continued by identifying the potential hazards and then risks analysis was conducted to obtain the risk level of each potential hazard. Results of the risks analysis are used as the basis for proposing the concept of ship design. The design will include: the characteristics of the operational environment of the ferry, the involvement of human factors and the functionality of the ship in relation to the safety aspects. It is projected that by implementing design for safety concept ferries accidents in Indonesia could be minimized.
\end{abstract}

Key words: Design, ferry, risk based, safety, implementing, potential

\section{INTRODUCTION}

Indonesia consists of more than 17,000 Islands, therefore, sea transportation plays very important role in the country's economic and political development as part of the national logistic system, smooth inter-island people movements and for claiming the sovereignty of the country. For connection between the islands crossing ferries and pioneer ships in many types and sizes are being utilized acting as bridges. Based on the data published by National Transportation Safety Committee (KNKT), Ministry of Transport Republic of Indonesia there were so many ship accidents happened on Indonesian waters and most of them were involving crossing ferries. Refer to the previous studies that had been conducted it was obvious that many of ferries operating in Indonesia were not designed, according to the safety requirements based on their intended operational conditions including those that were purchased from abroad. Combined with the latest development in ship design the study is aimed to propose a design concept for ferries operating on Indonesian waters that put safety as the main considerations which expected will reduce the number of ship accidents.

Definitions: Design is defined by Cambridge dictionary (Anonymous, 2018a) as a drawing or set of drawings showing how a building or a product is to be made and how it will work and look and according to Business dictionary (Anonymous, 2018b) design is defined as realization of a concept or idea into a configuration, drawing, model, mould, pattern, plan or specification and which helps achieve its designated objective (s). According to Webster dictionary (MW., 2019) safety is defined as the condition of being safe from undergoing or causing hurt, injury or loss.

Kuo (2007) stated that safety is not an absolute entity it can be interpreted from various points of view dependent on the context. Refer to the above definitions, therefore, design for safety can be defined as realization of a concept or idea into configuration, drawing, model that has relative freedom from danger, risk, injury or loss of personnel or property in accordance to its functionality.

Scope of the study: The study is focused on the concept of designing ferries to be operated on Indonesian waters which has certain kind of operational environment differences between one region and the others and put high emphasis on the safety aspects of the design.

Ship design for safety: Ship is a "unique" product as stated by Sunaryo et al. (2014), it has its special assigned missions and has to be designed in accordance to the owner's requirements and meet all the standards and regulations applied for it. Before a ship being constructed it should go through at least three design stages i.e., conceptual design, preliminary design and construction design or detail design. The main objectives of ship design are: to obtain a ship that will fulfill all range of its

Corresponding Author: Sunaryo, Department of Mechanical Engineering, Naval Architecture and Marine Engineering, Universitas of Indonesia, Kampus UI, 16424 Depok, Indonesia, naryo@eng.ui.ac.id 


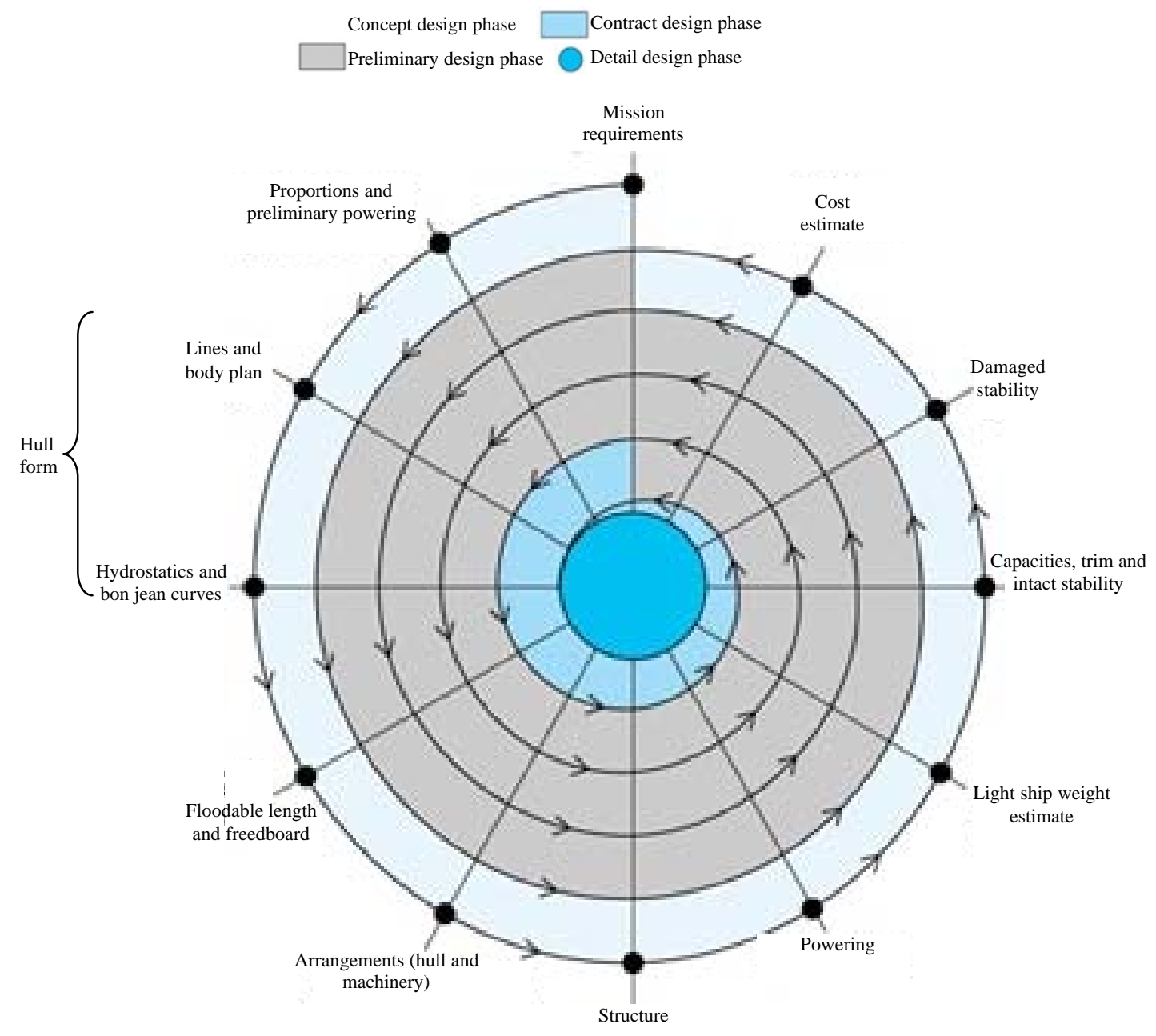

Fig. 1: Ship design spiral

16424 include operational performance and safety. To prepare a design that can be realized efficiently by the shipyard. To prepare a ship that will bring benefit to all parties concerned including the owner, the operator, the shippers and the society at large this is very much related to the operational performance of the ship, safety to the people and cargo and friendly to the environment.

Conventionally as introduced by Buxton (1976) a ship is designed through sequential and iterative processes which are known as design spiral as shown on Fig. 1. But the modern and innovative approach as suggested by Nowacki (2016) the design should include: system approach with product model, process model and concurrent engineering. Design process of system approach is illustrated on Fig. 2. With regard to the safety aspects Do Castelo stated ship safety is influenced by three factors, i.e., shipping, society and science and

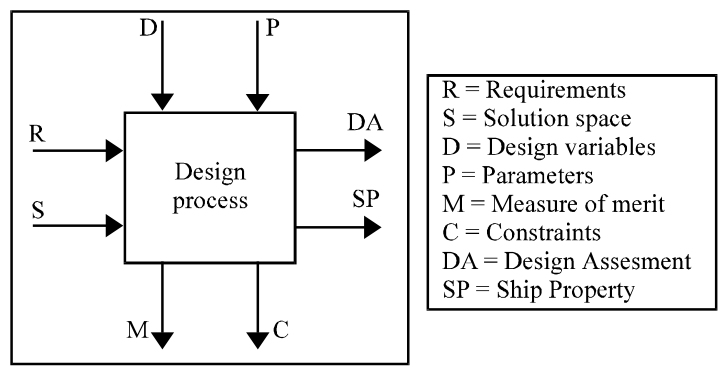

Fig. 2: System approach design process

technology. Shipping includes: the mission of the ship, main particulars, construction and area of operation. Society includes public expectation, public regard of human life and environment, international regulations and government policy. Science and technology includes: new innovation, engineering capability, etc. Generally, 
the existence of safety in design process is through the rule based approach which assumes that safety should be achieved by compliance with related rules and regulations but in reality based on accident investigation reports, rules and regulations can not anticipate the risks that may occur during the operation of the ship and as an alternative answer for this challenge risk based approach is proposed.

\section{MATERIALS AND METHODS}

The study was carried out using literature study on the recent approaches in ship and other similar subjects design, various reports of maritime safety researches and investigations, combined with available primary and secondary data including discussions with relevant stakeholders. Previous studies were reviewed in order to identify the main sources of past accidents and their root causes that related to the safety aspects of the design. Based on these findings the concept was constructed.

Accident data: Based on the accidents data published by the National Transportation Safety Committee (KNKT), Ministry of Transport Republic of Indonesia in the period of 2010-2016 there were 54 ship accidents occurred and claimed 337 human lives (NTSC., 2016). The types and percentage of the accidents were: $35 \%$ explosion and fire $31 \%$ collision $24 \%$ sinking $4 \%$ grounding and $4 \%$ others as shown on Fig. 1. According to Dunia Maritim there are four main sources of these accidents, i.e., human factors over loaded technical factors and weather condition and around $80 \%$ of the accidents were caused by human factor (Fig. 3).

Review on previous studies: Previous studies on various aspects of maritime safety had been conducted, since, 2010 with particular focus on crossing ferries operated on Indonesian waters such as navigation, fire, human factor, etc.

From navigation safety aspect, it was identified that $70 \%$ of ship being operated are considerably old and most of them were purchased as used ships from abroad, fiber glass and wooden boats are also being used on many crossing routes including on the inland and lake water ways on certain crossing routes the crossing lane are very congested such as between Merak and Bakauheni, Ketapang and Gilimanuk but in some places there are only a few ferries available. Only in large and busy crossing ports sufficient berthing facilities are available but in many places such as remote and small islands only simple wooden jetties are available. On most of the short crossing routes the vehicles on board are seldom being

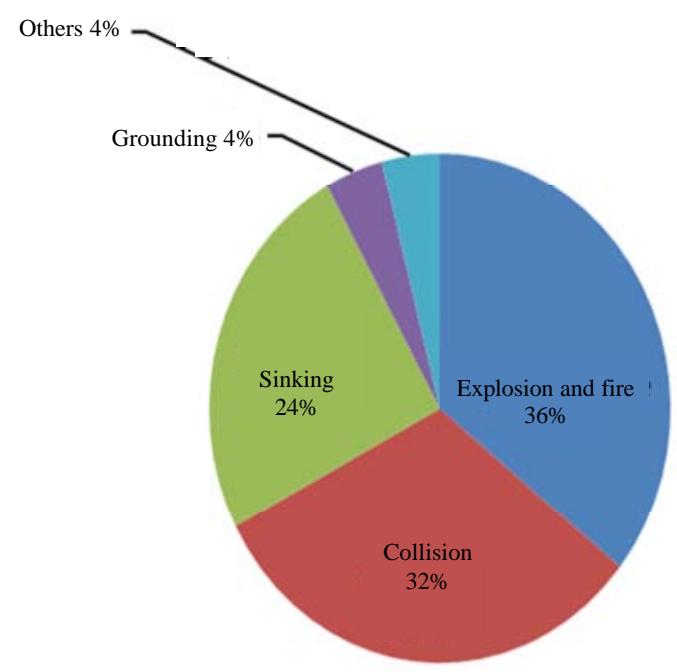

Fig. 3: Types and percentage of accidents occurred 2010-2016

lashed which in some cases negating the ship stability during bad weather. From fire safety aspect it is identified that: many of the crossing ferries are not equipped with proper fire safety equipment, improper arrangement and badly maintained of fire safety equipment, lack of fire safety information and improper ship layout in anticipating fire hazards. From human factor aspect it is evident that: the ship officers in general have appropriate professional competency but not the lower rank crews they do not have proper skill and knowledge for handling emergency situations. From the passengers aspect most of the passengers using the services are lowly educated people and do not have alternative transportation options, thus, do not have much awareness on safety issues.

Ship safety influencing factors: Ship safety is influenced by many factors among other things are: the ship itself the location where the ship is being operated people on board, the management, implementation of rules and regulations. Therefore, it is important to include the safety influencing factors in the design processes. The ship, the general arrangement including layout of ship spaces the arrangement of engine room, the decision of choosing main and auxiliary engines the material being used for ship construction and the installation of ship system and equipment are all have contributions to the ship safety. The location is the external factor that has influence to the ship safety such as the weather, wind, wave and current, water depth, navigation lanes, etc. People on board, the ship crews and the passengers will contribute to ship safety in positive as well as negative ways. The 
management will determine how well the ship being operated and maintained in order to achieve its safe operation cost affectively. Rules, regulations and port authority are acting as external enforcements for the ship (and its management) to comply with the safety standards.

Safety analysis: Safety analysis is carried out in order to identify potential hazards and risks that might emerge from them, so that, priority can be decided in arranging the safety strategy to be implemented in the design process. The stages of safety analysis are as follows: hazards identification, risk assessment, faults identification and accident sources identification.

Developments in ship design: Design is carried out as the process of conceiving the expected ship that would meet the owner's operational and functional requirements and comply with binding rules and regulations.

Rules and regulations are often seen as constrain by the naval architects because they seem restrict creative freedom of the designer. The conventional approach using sequential and iterative process known as prescriptive rule based ship design is very much restricted to the rules and regulations. In line with the fast development of science and technology, the ship design approach has much been changed in the way on how safety and risks are put into consideration which is known as risk based ship design or ship design for safety (Vasalos, 2012). Safety is treated as design objective rather than as restrictions, even though rules and regulations are still being used as formality references.

In conjunction with the new design approaches, International Maritime Organization (IMO) through its Marine Safety Committee (MSC) has adopted revised safety requirements for passenger vessels in the event of flooding caused by an incident Ventura, 2018) and classification societies such as Lloyd Register of Shipping have adopted risk based design approach in their rules and regulations which require hazards identification and risks assessment to be included into the proposal for design approval.

\section{RESULTS AND DISCUSSION}

Based on the lesson learned from the previous studies on the ferry safety, combined with latest development in ship design approaches, ship design for safety is appropriate to be implemented on the design of ferries for operation on Indonesian waters. Reasons behind it are because there are many individual unique characteristics of the crossing regions in Indonesia which must be given special attention in relation to the safety objectives of the design.

Results from previous studies: Findings from the previous studies on the safety of the ferries operated on Indonesian waters concluded that: $70 \%$ of ship being operated are considerably old, beside steel vessels fiber glass and wooden boats are also being utilized as crossing ferry, some of the crossing routes are very congested but in other places are relatively quiet some ports do not have sufficient facilities. Most of the ferries are far from sufficiently equipped with safety equipment many small ferries are poorly designed, manned with incompetent crews and majority of the passengers are from low educated people who do not have much knowledge on safety awareness.

Design for safety concept: Design for safety concept has been adopted for ship design processes both by International Maritime Organization and classification societies. Since, there were so, many ship accidents in Indonesia, particularly involving crossing ferries it is assumed that the design for safety concept should be appropriate to be adopted for designing ferries to be operated on Indonesian waters as an anticipation for the rejuvenating the existing fleet.

Potential hazards conceived in the ferry should be identified followed by risk assessment for obtaining the design criteria, results of the design are then matched with the safety standards required by statutory regulations and classification rules.

Design considerations for ferries to be operated on Indonesian waters are: ship stability with low draft and low point of metacentric, no longitudinal bulkhead on the car decks, passenger's behavior, weather condition including high wave, strong wind and current, limited berthing facilities at the port, etc.

\section{CONCLUSION}

Safety is a non absolute entity and related to the potential hazards and the level of risks, therefore, design for safety using risk based approach rather than rules based approach is relevant to be implemented for designing ferries intended for operation on Indonesian waters because of the many different operational requirements on Indonesian waters.

\section{ACKNOWLEDGEMENT}

Parts of the study have been presented as key note paper in International Conference on Automotive, 
(Manufacturing and Mechanical Engineering, 2018) in Bali. The researchers would like to express their appreciation to the Ministry of Research Technology and Higher Education Republic of Indonesia for providing research fund to conduct the study and to the Directorate of Research and Community Engagement Universitas Indonesia for facilitating the research.

\section{REFERENCES}

Anonymous, 2018a. Design definition. WebFinance Inc., San Antonio, Texas. http://www. businessdictionary. $\mathrm{com} /$ definition/design.html

Anonymous, 2018b. Meaning of design in English. Cambridge University Press, Cambridge, UK. https://dictionary.cambridge. org/dictionary/english $/$ design

Buxton, I.L., 1976. Engineering Economics and Ship Design. 2nd Edn., British Ship Research Association, England, UK., ISBN:9780950276823, Pages: 107.

Kuo, C., 2007. Safety Management and its Maritime Application. Nautical Institute, London, UK., ISBN: 9781870077835 , Pages: 288.
MW., 2019. Definition of safety. Merriam-Webster, Springfield, Massachusetts, USA. https://www. merriam-webster.com/dictionary/safety.

NTSC., 2016. Ship accidents investigation data 201 0-2016. National Transportation Safety Committee, Indonesia.

Nowacki, H., 2016. A farawel to design spiral. Proceedings of the Mini-Symposium on Ship Design, Ship Hydrodynamics and Maritime Safety, September 30, 2016, Berlin Institute of Technology, Berlin, Germany, pp: $1-23$.

Sunaryo, S., Y. Nugroho and A. Azhary, 2014. Simulation analysis of fire safety system onboard Indonesia Ro-Ro PaxCrossing Ferries. J. Technol., 69: 149-152. Vasalos, D., 2012. Design for safety: Risk-based design. Ship Stability Research Center, North Portland Street, Glasgow, UK.

Ventura, M., 2018. Legislations, rules and standards in the design of merchant ship. Instituto Superior Tecnico, Lisboa, Portugal. http://www.mar.ist.utl.pt/ mventura/Projecto-Navios-I/EN/SD-1.2.1-Rules\% 20\&\%20Regulations.pdf. 